\title{
THE USE OF THE RESULTS OF READING TESTS AS BASES FOR PLANNING REMEDIAL WORK
}

W. L. UHL

Northwestern University

In connection with courses in educational measurements offered at the Oshkosh State Normal School during the past summer, the writer had an opportunity to use the results of the tests in reading as bases upon which to plan remedial work for defects in reading. The purpose of this paper is to set forth some of the results of this work as measured by the tests themselves.

A word should be said at the outset regarding the pupils upon whom the tests were made. These pupils, like those who usually attend the summer session of public or training schools, were, to a large degree, either conditioned or retarded in their school work. For this reason the low scores attained by many of the pupils are in no sense a measure of the work of the Oshkosh schools as a whole. Also it should be said that, of those who were neither conditioned nor retarded, many were just beginning new grades. Consequently their scores do not necessarily represent the work they would do if tested at the time of year that the standard scores for the different reading tests were derived.

Method.-Very soon after the opening of the summer school, the Kansas silent-reading tests were given to all training-school pupils of Grades III to VIII inclusive. The papers were scored at once and the results were tabulated by grades. Table I shows the results for this test. With these results at hand it was possible roughly to judge the character of the training-school pupils and to plan further work.

As the school term was short, it was necessary to select as early as possible the pupils who were in greatest need of attention. While the Kelly tests indicated roughly who these pupils were, it was desired that further evidence be secured. The next day, therefore, individual testing with the Gray oral-reading scale was 
begun, those pupils having the lowest scores in the Kelly tests being tested first. This method rendered unnecessary the testing individually of the entire number of pupils before locating many pupils who were in need of individual instruction. In giving the Gray tests it was possible also to detect, in many instances, several causes for poor reading in individual cases. These individual defects were, in all cases, noted in connection with the records of the pupils.

TABLE I

Results of the Kelly Tests Both Before and after the Drill Lessons

\begin{tabular}{|c|c|c|c|c|c|c|c|c|c|c|c|c|c|}
\hline & \multirow{3}{*}{ SCORES } & \multicolumn{12}{|c|}{ Grades } \\
\hline & & \multicolumn{2}{|c|}{ III } & \multicolumn{2}{|c|}{ IV } & \multicolumn{2}{|r|}{$\mathrm{v}$} & \multicolumn{2}{|c|}{ VI } & \multicolumn{2}{|c|}{ VII } & \multicolumn{2}{|c|}{ VIII } \\
\hline & & $\begin{array}{l}\mathrm{Be}- \\
\text { fore }\end{array}$ & After & $\begin{array}{c}\mathrm{Be}- \\
\text { fore }\end{array}$ & After & $\begin{array}{c}\mathrm{Be}- \\
\text { fore }\end{array}$ & After & $\begin{array}{c}\mathrm{Be}- \\
\text { fore }\end{array}$ & After & $\begin{array}{c}\text { Be- } \\
\text { fore }\end{array}$ & After & $\begin{array}{c}\text { Be- } \\
\text { fore }\end{array}$ & After \\
\hline o to & 0.9. & 5 & 2 & $\cdots$ & $\cdots$ & $\cdots$ & $\cdots$ & $\mathbf{I}$ & $\circ$ & & & & \\
\hline I. O to & I. $9 \ldots \ldots$ & 2 & 3 & $\mathbf{I}$ & 0 & $\ldots$ & . & 2 & $\circ$ & $\ldots$ & ... & $\cdots$ & $\ldots$ \\
\hline 2.0 to & $2.9 \ldots \ldots$ & 2 & 2 & 2 & 3 & $\ldots$ & & $\mathbf{I}$ & $\circ$ & $\mathbf{I}$ & 0 & & $\ldots$ \\
\hline 3.0 to & $3 \cdot 9 \ldots \ldots$ & 2 & $\circ$ & 6 & I & 2 & $\circ$ & $\circ$ & 0 & $\mathbf{I}$ & 0 & $\ldots$ & $\ldots$ \\
\hline 4.0 to & $4.9 \ldots \ldots$ & 0 & 2 & 2 & $\circ$ & I & $\circ$ & 2 & I & $\circ$ & $\circ$ & $\cdots$ & $\cdots$ \\
\hline 5.0 to & $5.9 \ldots \ldots \ldots$ & I & 2 & 2 & 3 & I & $\circ$ & I & o & 0 & 0 & & $\ldots$ \\
\hline 6.0 to & $6.9 \ldots \ldots$ & I & 0 & 3 & I & I & 2 & 2 & $\circ$ & $\circ$ & $\circ$ & I & $\circ$ \\
\hline 7.0 to & $7 \cdot 9$ & 0 & I & 3 & 3 & 2 & $\circ$ & $\circ$ & $\mathbf{I}$ & $\circ$ & 0 & $\circ$ & 0 \\
\hline 8.0 to & $9 \cdot 9$. & I & I & 2 & 3 & 4 & 3 & 3 & I & 2 & 0 & $\mathbf{I}$ & $\circ$ \\
\hline I0.0 to & I $2.9 \ldots \ldots \ldots$ & 0 & I & 2 & 2 & 2 & 3 & 4 & 5 & 2 & I & 4 & 3 \\
\hline I 3.0 to & $I_{5} \cdot 9 \ldots \ldots$ & 0 & $\circ$ & $\circ$ & 6 & I & 5 & 3 & 2 & 5 & 4 & 2 & 3 \\
\hline I 6.0 to & $I_{7} .9 \ldots \ldots$ & 0 & $\circ$ & $\circ$ & I & 6 & 4 & 2 & 2 & $\circ$ & $\circ$ & 2 & o \\
\hline I 8.0 to & $19.9 \ldots \ldots$ & 0 & $\circ$ & $\circ$ & $\circ$ & $\mathbf{I}$ & I & $\circ$ & 4 & 2 & 3 & 3 & $\circ$ \\
\hline 20.0 to & $22.9 \ldots \ldots$ & 0 & $\circ$ & $\circ$ & $\circ$ & $\mathbf{I}$ & 2 & $\circ$ & 3 & $\circ$ & I & 3 & 2 \\
\hline 23.0 to & $24.9 \ldots \ldots$ & 0 & $\circ$ & 0 & $\circ$ & $\circ$ & $\circ$ & $\circ$ & I & $\mathbf{I}$ & I & 3 & 4 \\
\hline 25.0 to & $29.9 \ldots \ldots \ldots$ & 0 & $\circ$ & $\circ$ & $\circ$ & $\circ$ & 2 & $\circ$ & I & $\circ$ & 2 & 2 & 5 \\
\hline 30.0 to & 34.9. & 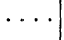 & $\cdots$ & $\cdots$ & $\ldots$ & $\cdots$ & . & $\cdots$ & $\cdots$ & $\ldots$ & I & 3 & 5 \\
\hline 35.0 to 3 & 39.9 & & & $\cdots$ & $\cdots$ & $\cdots$ & $\cdots$ & $\cdots$ & $\cdots$ & $\cdots$ & I & $\circ$ & $\circ$ \\
\hline 40.0 to & $44 \cdot 9$ & $\cdots$ & .. & $\cdots$ & $\cdots$ & $\cdots$ & $\cdots$ & 1 & $\ldots$ & $\cdots$ & 0 & $\circ$ & $\circ$ \\
\hline 45.0 to & 49 . & $\cdots$ & $\cdots$ & $\cdots$ & $\cdots$ & $\cdots$ & $\cdots$ & . . & $\cdots$ & $\cdots$ & $\cdots$ & I & $\mathbf{I}$ \\
\hline 50.0 to. & & $\cdots$ & & i & $\cdots \cdots$ & $\cdots$ & - & $\cdots$ & $\cdots$ & $\cdots$ & $\cdots$ & $\cdots$ & 2 \\
\hline Tot: & tal. & I4 & I4 & 23 & 23 & 22 & 22 & $2 \mathrm{I}$ & $2 \mathrm{I}$ & 14 & I4 & 25 & 25 \\
\hline Med & dians. & 2.0 & $3 \cdot 5$ & $5 \cdot 5$ & 8.7 & 10.0 & 14.8 & $9 \cdot 3$ & 17.0 & I3.6 & 19.3 & 20.0 & 26.0 \\
\hline Gair & & $\ldots$ & I. 5 & $\cdots$ & 3.2 & $\cdots$ & 4.8 & $\cdots$ & $7 \cdot 7$ & T. & $5 \cdot 7$ & 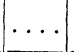 & 6.0 \\
\hline Kan & nsas standards. & 6.0 & & $9 \cdot 9$ & & I3.7 & & I3.4 & & I6.5 & & I8.8 & \\
\hline
\end{tabular}

In the oral reading of a few pupils there were no noticeable defects. Some of these pupils were obviously misplaced by their work with the Kelly tests. Such pupils had failed to do well on 
account of such causes as a slight indisposition, a broken pencil point, or failure to understand the nature of the test. An example of a rather bright boy failing to understand the nature of the tests was encountered in the case of a sixth-grade pupil who made a score of zero on the first Kelly test, following this with a score of 47 with the Gray test, and a good score in other succeeding tests. Such individual cases are found in nearly every class tested with the Kelly tests. There were also a few pupils who did well in the Gray oral-reading test, but who did not appear to be intelligent readers. These pupils were then given a third test-the Gray silent-reading test. In one or the other of the tests it is believed that all the poor readers were located and their cases diagnosed with a fair degree of accuracy.

Our diagnosis included several matters which were shown objectively upon the test sheets; other defects, such as a lack of intelligent interpretation, hesitancy, and gross bodily movements, were noted in our additional records. When assignment to a student-teacher was made, these records were carefully gone over, and plans were made for specific treatment of defects. This treatment was continued or modified during the training period according to the apparent needs of the pupils. Individual drill periods of fifteen minutes a day were used regularly for each of the pupils showing marked defects. This drill was continued for a period of from two to three weeks.

At the end of the six-weeks term all pupils in the school were given the Kelly tests for the second time, and all those trained individually, together with a random sampling of the others, were given the Gray oral-reading test for the second time. By means of the results of these second tests it is possible to show in an objective manner some of the results of our individual training.

Results and discussion of special methods.-A discussion of the results of the tests and drill should contain at least a brief treatment of some of the results which do not appear in the scores made by the pupils. For example, some pupils may be found to make low scores on account of extreme care, others on account of extreme carelessness. One fifth-grade girl, much retarded, is an example of extreme carelessness. Each time she worked through both of 
the first two pages, but received a score of 6.5 and 8.3 , respectively, in the two tests instead of a possible 23.8 in case all trials had been successful. Her particular difficulty was found to be a mispronunciation of small words. Her scores in the Gray oral tests were $3^{2} .5$ and $3 \mathrm{I} .3$, respectively, in spite of the fact that she was given individual drill for three weeks.

Another typical form of defect is shown in the case of a fourthgrade boy who worked to the middle of the second page of the Kelly test in his first trial, only two out of nine paragraphs being correctly worked. This boy underscored all words when asked to underscore only one, as in No. 6 , and put a line around all words in the list in No. 9. He seems also to have carried mentally the word "red" from paragraph No. I to paragraph No. 7, which has to do with the erasure of certain letters.

Reading which was poor on account of its slowness was found in the case of two girls of the upper grades who seemed to need much more than mere exhortation to work rapidly. Both oraland silent-reading drills were used in training these girls, with the result that their reading improved in such matters as general expression as well as in the case of factors measured by the tests.

Evidences of errors shown in the records of the tests were suggestive of possible remedies in many cases, for example, that of a boy who showed by his first oral test that much of the trouble lay in his failure to note carefully such words as "had," "ran," "the," "then," and "dog" in the first paragraph of the Gray test, and who read "pass" for "puss," "kind," for "king," and "house" for "room." In most cases the word substituted showed no relation to the meaning of the passage. This type of difficulty was treated by giving drill upon very easy and very interesting reading material. ${ }^{x}$ Particular attention to the meaning of the selections read was secured by directing his attention to the story element. In addition to this, drill was given in reading short, easy sentences until they were read correctly several times in succession. This boy's oral-reading score improved from 13.8 to 27.5 largely on account of more accurate reading of the words noted above. The gain as

I This material consisted of selections from several readers used in lower grades. Among them were the Free and Treadwell, "Story Hour," Elson, and "Riverside." 
shown by the Kelly test was of about the same character. Although the gains shown by this boy's records are probably due partially to indirect factors, as general toning up, yet his improvements from day to day indicate that much benefit came from the specific kind of drill used.

Another common error-that of reading word by word rather than by thought groups, was found in several pupils. One boy who showed this defect to a marked degree was told in oral reading to "look ahead" several words and to be certain before beginning to read each succeeding group that he could read through the single group connectedly. No attempt was made at first to have him read as a group more than the minimum number of words required for each thought group of words. This boy's oral-reading score improved from 23.8 to 33.8 in the two tests; in the Kelly tests he improved from 5.9 to 9.3 .

In case of defects already described, as well as of others, a large part of the drill period was spent in reading easy, interesting material. This kind of material was used for two reasons: (I) it offered opportunity for concentration upon errors which the pupil was able to avoid by careful reading, and (2) such material could be selected from the mass of very interesting folk-tales, thus securing a story element which made emphasis upon meaning relatively easy. For such defects as were shown in failure to do well in the Gray silent-reading tests for the upper grades it was found to be well in some cases to drill pupils upon both easy, interesting material and upon harder, abstract material. In such drills certain points touched upon in the selection were sometimes mentioned to the pupil before he began to read; at other times a synopsis was asked for or questions presented after reading. The need for effort upon the part of the pupil was emphasized in such cases. ${ }^{\mathbf{X}}$

The gains made and the general interest and toning up shown by several of these pupils are sufficient at least to indicate what might be done in a longer training period for pupils who are averse to the reading of books and who fail to make satisfactory progress as a result of class instruction only. It seems quite possible that

I In these drills many of the devices used were similar to those suggested by by N. E. Turner in Teaching to Read (American Book Co., I915). 
with some drill, together with a motive for reading, these pupils would lose much of their aversion to books.

Table II shows the records made by all the pupils who took the Gray oral-reading test and the Kelly test at both the beginning and the end of the term. The results of the Gray silent-reading tests are not shown, because lack of time prevented our giving them to many besides those whose defects were not easily found by means of the other tests. This table shows in the first column the Kansas

TABLE II

Comparative Results of Those Drilled Individually and Those Not So Drilled The Upper Section Gives Results of the Kelly

Tests, the Lower of the Gray Tests

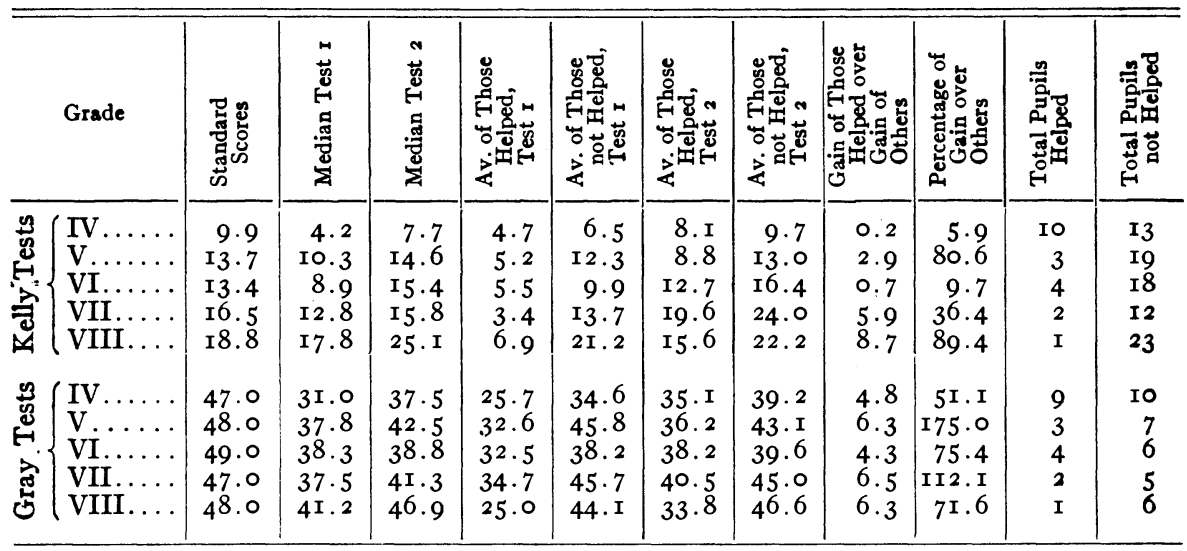

standards for the Kelly tests. The second and third columns show the Oshkosh results for the first and second trials, respectively, for the whole group. In the next columns are data which make possible a comparison of growth of the pupils given individual aid with the growth of pupils given only regular school work. The portion of the table dealing with the Gray tests is similarly arranged. In considering the relative growths, it should be stated that between the tests no reference was made to the tests themselves, all drill being upon other material than that contained in any tests. It should also be borne in mind that the pupils who were given individual attention were the poorest readers in the school and were, presumably, not as bright as those who were not selected for the 
drill. This is true of all except the two shown in Grade IV as having good scores for the first test; these two were accidentally drilled upon reading for several days instead of upon arithmetic as was intended, the work being continued for several days longer to see what the effect would be. The scores of the pupils of Grade III are omitted because none of those drilled by the students were present for the tests at the end of the term.

Column 9 in each part of the table shows the percentage gain of those drilled individually over those who were not drilled. This was found by dividing the "gain of those helped over the gain of others" by the gain of those helped. While the number of pupils in each of the grades is small, yet the presence of a large relative gain in each grade upon the part of those drilled seems significant. Except in the case of the eighth grade, there is at least a rough parallelism between the gains made in the scores of the different tests. If the small number of pupils will warrant another conclusion, it might be said that the gain in case of the Kelly test indicates that reading rather than general intelligence is measured by the test; a gain in general intelligence upon the part of those drilled would hardly be expected to overcome differences so great as were shown in the first trial.

In order to facilitate comparison of the scores of the pupils who received individual attention with those who did not, Table III is given. The figures are based upon the class averages given in Table II. The first two columns show the differences between the class averages in the two tests; the third and fourth columns were found by dividing these differences by the initial scores.

Table IV shows the results of the tests as to ranges. The pupils referred to as "those helped" are those who were given individual attention. A comparison of the ranges for the first and second tests shows that there was a considerable reduction in the disparity of the work of the pupils of each grade in case of those who were helped individually. Neither the table showing ranges nor Table I showing distributions by grades indicates the extent to which the disparity was reduced; if, however, Tables I and IV are compared, it will be seen that, with the exception of one pupil, all those who were drilled show a marked tendency to gravitate toward the class median. 


\section{TABLE III}

Comparative Gains and Percentage Gains of the Pupils Who Were Drilled and Those Who Were Not Drilled

\begin{tabular}{|c|c|c|c|c|c|}
\hline & Grade & $\begin{array}{l}\text { Gain of Those } \\
\text { Helped }\end{array}$ & $\begin{array}{l}\text { Gain of Those } \\
\text { Not Helped }\end{array}$ & $\begin{array}{l}\text { Percentage Gain } \\
\text { of Those Helped }\end{array}$ & $\begin{array}{c}\text { Percentage Gain } \\
\text { of Those Not } \\
\text { Helped }\end{array}$ \\
\hline Kelly tests... & $\left\{\begin{array}{l}\text { IV } \ldots \ldots \ldots \\
\text { V } \ldots \ldots \ldots \\
\text { VI. } \ldots \ldots \ldots \\
\text { VII } \ldots \ldots \ldots \\
\text { VIII } \ldots \ldots \ldots\end{array}\right.$ & $\begin{array}{r}3.4 \\
3.6 \\
7.2 \\
16.2 \\
9.7\end{array}$ & $\begin{array}{r}3.2 \\
0.7 \\
6.5 \\
10.3 \\
1.0\end{array}$ & $\begin{array}{r}71 \\
69 \\
131 \\
476 \\
141\end{array}$ & $\begin{array}{r}49 \\
6 \\
66 \\
75 \\
5\end{array}$ \\
\hline Gray tests... & $\left\{\begin{array}{l}\text { IV } \ldots \ldots \ldots \\
\text { V } \ldots \ldots \ldots \\
\text { VI } \ldots \ldots \ldots \\
\text { VII } \ldots \ldots \ldots \\
\text { VIII } \ldots \ldots \ldots\end{array}\right.$ & $\begin{array}{l}9.4 \\
3.6 \\
5.7 \\
5.8 \\
8.8\end{array}$ & $\begin{array}{r}4.6 \\
-\quad 2.7 \\
1.4 \\
-0.7 \\
2.5\end{array}$ & $\begin{array}{l}37 \\
\text { I I } \\
\text { I } 7 \\
\text { I } 7 \\
35\end{array}$ & $\begin{array}{r}13 \\
-\quad 6 \\
-37 \\
-\quad 2 \\
6\end{array}$ \\
\hline
\end{tabular}

TABLE IV

Showing Range of Scores Made in Kelly and Gray Tests

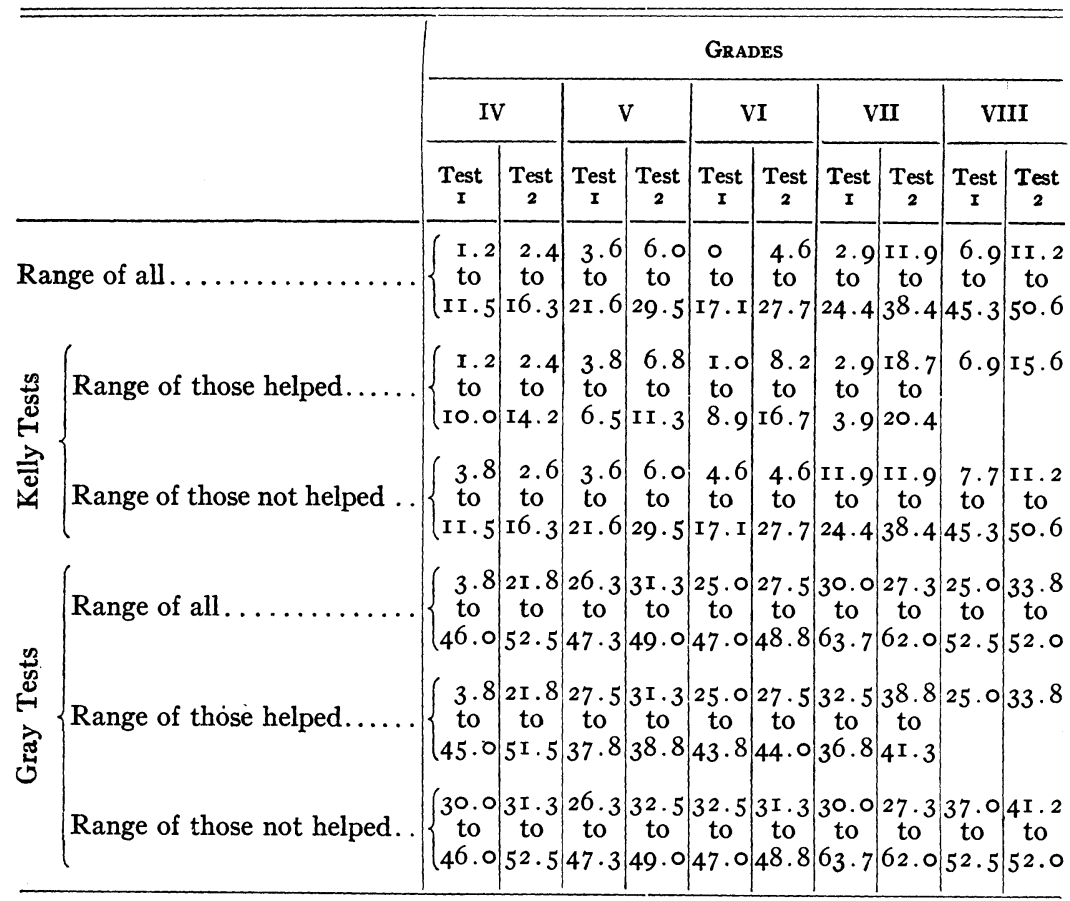


Table $\mathrm{V}$ shows the individual gains made by the pupils of the fourth grade. Some of these should be discussed briefly. The first one, A. K., made little gain as shown by the Kelly tests; at the beginning of the practice period he read very loud and made many

TABLE V

Individual Records for PupILs of Grade IV

\begin{tabular}{|c|c|c|c|c|c|c|c|c|c|c|}
\hline \multirow{2}{*}{ PupiL } & \multicolumn{4}{|c|}{ KeLly Tests } & \multicolumn{4}{|c|}{ Gray Orat-Reading Tests } & \multicolumn{2}{|c|}{$\begin{array}{c}\text { Gray Sinent- } \\
\text { REading Tests }\end{array}$} \\
\hline & Test I & Test 2 & Gain & $\begin{array}{c}\text { Percent- } \\
\text { age of } \\
\text { Gain }\end{array}$ & Test I & Test 2 & Gain & $\begin{array}{c}\text { Percent- } \\
\text { age of } \\
\text { Gain }\end{array}$ & Rate & Quality \\
\hline $\mathrm{K}$ & I. 2 & 2.4 & I. 2 & 100 & $7 \cdot 5$ & 27.5 & 10.0 & $5 \mathrm{I} .7$ & .62 & 4.0 \\
\hline & 2. & 7.4 & 4 & 18 & 3 & & $2 . I$ & 6.6 & I. 3 & 6.0 \\
\hline C.L. & 2.6 & 5.4 & 2.8 & 107 & $3^{2} .5$ & 35.0 & 2.5 & $7 \cdot 7$ & I. 2 & 10.0 \\
\hline M.F.* & 3.4 & II. I & $7 \cdot 7$ & 226 & 31.7 & $4 \mathrm{I} .3$ & 9.6 & 30.3 & .8 & 8.0 \\
\hline $\mathrm{K}$ & 3. & $5 \cdot 9$ & $2 . I$ & 55 & 13.8 & $2 \mathrm{r} . \overline{8}$ & 8.0 & 57.9 & $.6 \mathrm{I}$ & 22.0 \\
\hline 1.3. & 3. & 6.8 & 3.0 & 79 & 3 & 33.8 & 30.0 & 789.5 & .9 & .0 \\
\hline & 3. & 2.6 & -1.2 & $-3^{2}$ & 25 . & & & & 1.8 & 7.0 \\
\hline 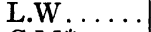 & 3. & 2.6 & $-\mathrm{I} .2$ & $-3^{2}$ & 25.0 & & & & $\ldots$ & \\
\hline C. 1 & 3. & $7 \cdot 7$ & 2.9 & 76 & 31.8 & $37 \cdot 5$ & $5 \cdot 7$ & 17.8 & I. 2 & 5.0 \\
\hline $\mathrm{C}$ & 4. & 7. & 3 . & 90 & $3^{8} \cdot 3$ & 41.8 & 3 & 9.1 & & $\ldots$ \\
\hline $\mathbf{M}$ & 4. & I5.2 & II.O & 275 & 43.8 & 45.0 & I. 2 & 2.0 & $\cdots$ & . \\
\hline & 5. & 3.8 & -1.8 & -32 & & & & & & \\
\hline & 5. & 9. & $3 \cdot 4$ & $5^{8}$ & 23 . & 8 & 10.0 & 41.6 & & \\
\hline & 6. & 13.6 & $7 \cdot 3$ & II 6 & 30.0 & 51.5 & 21.5 & 71.6 & $\ldots$ & \\
\hline & 6. & $\pi$ & I. 4 & 02 & 0 & 40.0 & 2.0 & 5.2 & 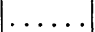 & .. \\
\hline & 6. & 8 & I. & I & 36.3 & 3 I. 3 & -6.0 & -16.5 & & \\
\hline & 7.4 & 9. & I. 7 & 22 & 41.3 & 37.5 & -3.8 & -9.2 & 1. & - \\
\hline & 7. & I3. & $5 \cdot 7$ & 74 & 22.5 & & $\ldots \ldots$ & $\ldots \ldots$ &. & . \\
\hline & 7. & & 5 & 7 & & 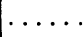 & $\cdots$ & & & \\
\hline & 8. & I6. & 7. & 83 & 30.0 & $47 \cdot 5$ & 17.5 & 58.3 & . & . \\
\hline & 9. & 10.9 & I. 3 & 14 & 41.0 & 46.5 & $5 \cdot 5$ & I3.4 & . & . . \\
\hline W & 10. & I4. & 4. & 42 & & 51.5 & & 14.4 & & \\
\hline G.S & II. $\dot{5}$ & I4. 6 & $3 . I$ & 27 & 46.0 & 52.5 & 6.5 & $44 . \mathrm{I}$ & $\cdots$ & $\ldots$ \\
\hline Totals . . & 23 & 23 & & & 22 & I8 & & & 8 & 8 \\
\hline Medians & 5.6 & 8.0 & 3.0 & 73 & 31.8 & 40.0 & 6.5 & I 7.8 & I. 2 & 7 \\
\hline
\end{tabular}

*Given individual drill.

gross bodily movements. He was drilled upon easy material orally only. O.S. and W.F. were drilled for five days; their failure to profit may be due to the very short period of drill and to the fact that they were not drilled for any specific difficulty. The pupil making the greatest gain in oral reading, A.S., read in the first test only paragraphs I to 4 of the Gray test; she made 9 errors in the first paragraph and 12 in the fourth. In the second test she made 
only 2 errors in the first paragraph and 4 in the fourth and was allowed to read through the seventh in which she made 8 errors. Her typical error was that of repeating the first words of each sentence; her gain consists chiefly in the reduction of the number of times that she made such repetitions.

Conclusions.-While the number of cases represented in this study is inadequate for the drawing of positive conclusions, yet the data given tend toward the following:

I. As a means of diagnosis the Kelly test supplemented by the Gray tests should prove very valuable to any superintendent, but especially so to one entering a new system.

2. The accuracy of the diagnosis is such that no poor readers will be found to make good records in all tests, while the specific defects of poor readers can be detected.

3. The keeping of additional records as to specific defects is valuable as indicating or suggesting means for improvement.

4. For many of those who fail to profit by class instruction, carefully planned individual treatment will produce as rapid growth as is produced in case of many apparently brighter pupils by class instruction.

5. Drill should be carried on during the school day by those who are experienced in teaching the subject. (All those who aided in this study had had some experience in teaching young children.)

6. As a measure of economy of school pupils if not of money, unassigned teachers should be available for every superintendent's use in giving individual attention to pupils who are or will soon be in the retarded group. 